\title{
Effect of Sand Relative Density on Response of a Laterally Loaded Pile and Sand Deformation
}

\author{
Bingxiang Yuan, ${ }^{1}$ Rui Chen, ${ }^{1}$ Jun Teng, ${ }^{1}$ Yixian Wang, ${ }^{2}$ Wenwu Chen, ${ }^{3}$ Tao Peng, \\ Zhongwen Feng, ${ }^{1}$ Yang $\mathrm{Yu}^{4}{ }^{4}$ and Jianghui Dong ${ }^{5}$ \\ ${ }^{1}$ Shenzhen Graduate School, Harbin Institute of Technology, Shenzhen 518055, China \\ ${ }^{2}$ School of Civil Engineering, Hefei University of Technology, Hefei 230009, China \\ ${ }^{3}$ School of Civil Engineering and Mechanics, Lanzhou University, Lanzhou 730000, China \\ ${ }^{4}$ Centre for NanoScale Science \& Technology and Centre for Maritime Engineering, Control and Imaging, School of Computer Science, \\ Engineering and Mathematics, Flinders University, Adelaide, SA 5042, Australia \\ ${ }^{5}$ School of Natural and Built Environments, University of South Australia, Adelaide, SA 5095, Australia
}

Correspondence should be addressed to Rui Chen; ruichen122005@126.com

Received 28 August 2014; Accepted 24 September 2014

Academic Editor: Tifeng Jiao

Copyright (c) 2015 Bingxiang Yuan et al. This is an open access article distributed under the Creative Commons Attribution License, which permits unrestricted use, distribution, and reproduction in any medium, provided the original work is properly cited.

\begin{abstract}
Two scale-model tests were separately conducted in standard Toyoura sand with relative density of $50 \%$ and $80 \%$. The effect of sand relative density on pile-soil interaction was investigated through the response of a laterally loaded pile and the sand movement around the pile. At a displacement of $3.6 \mathrm{~mm}$ of the loading point, the applied loads in loose and dense sand were $4.775 \mathrm{~N}$ and $21.025 \mathrm{~N}$, respectively, and the maximum moment and soil resistance of the pile in dense sand were over 4 times those in loose sand. However, the deflection of the pile in dense sand was less than that in loose sand; additionally, the depth of zero deflection in dense sand was also less than that in loose sand. At the same time, the maximum displacements of loose sand in the vertical profile and ground surface were over 1.5 times those of dense sand. These characteristics occurred because the relative stiffness ratio of soil and pile increased as the relative density increased, which caused the behavior of the pile in dense sand to be elastic rather than rigid. In addition, the compacted sand particles did not move as easily as the loose sand particles.
\end{abstract}

\section{Introduction}

Many transmission towers, high-rise buildings, and bridges are supported by piles $[1,2]$. These structures not only bear axial loads but also are subjected to considerable lateral loads such as violent winds and earthquakes [3]. Therefore, the lateral loading capacity of piles is an important design consideration for the construction of deep foundations [4]. Many approaches have been proposed to analyze the lateral loading capacity, such as the Broms method [5], the elastic method [6], the $p-y$ curve approach $[7,8]$, and the strain wedge method $[9,10]$.

Most of research about the laterally loaded pile has been carried out by attaching strain gauges on piles to measure the lateral loading capacity, pile deflection, and soil resistance created by the pile $[11,12]$. It is worth noting, however, that the behavior of the laterally loaded pile depends on soil reaction and vice versa. Only a few model tests had been used to study the movement of the soil around the pile. Of those, Otani et al. [13] used X-ray computed tomography (CT) to investigate three-dimensional deformation of the sand around a laterally loaded pile. Due to the high cost of the CT scanners, this technique has limited application in the geotechnical engineering. With the development of digital image processing, an economical, accurate, and full field image correlation technique, termed as particle image velocimetry (PIV), has been used in geotechnical engineering [14]. Liu et al. [15] and Yuan et al. [16, 17] used the PIV technique to correlate two consecutive images and measure the displacement fields of the ground surface around a pile under lateral loading.

This study presents the results from two scale-model tests done in dense and loose sand to determine the effects of relative density on the response of a laterally loaded pile 


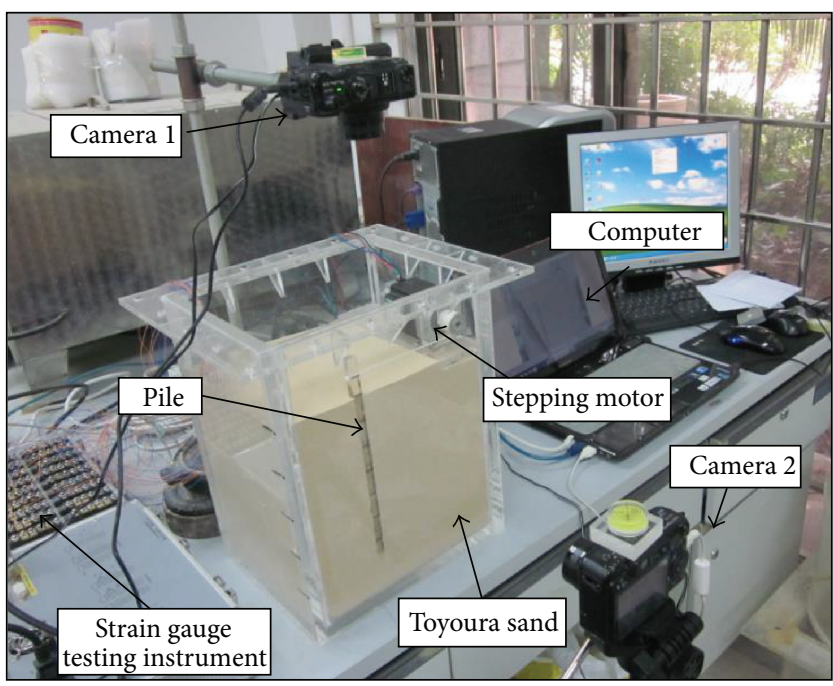

FIgURE 1: The optical experimental setup.

and on the surrounding soil deformation. Combined with horizontal and vertical displacement fields measured using a PIV technique, the bending moment, lateral deflection, and soil resistance distribution along the model pile as derived from strain measurements were also analyzed. Our findings indicate that the effect of relative density on soil-pile interaction can be evaluated quantitatively.

\section{Experimental Setup and Test Procedure}

2.1. An Optical Experimental Setup. As shown in Figure 1, the optical experimental setup included a model box, a model pile, two cameras placed on the top and side of the model box, a stepping motor with a driver to apply lateral loading, and a data acquisition system to collect strain data.

A Plexiglas box $300 \mathrm{~mm}$ in height, $200 \mathrm{~mm}$ in width, and $250 \mathrm{~mm}$ in length was used as the model box. The pile was a square section of Plexiglas with a width of $10 \mathrm{~mm}$ and a flexural rigidity of $50 \mathrm{~N} \cdot \mathrm{m}^{2}$. The model pile was embedded $210 \mathrm{~mm}$ deep with a section extending approximately $40 \mathrm{~mm}$ above the surface. The lateral loads were applied using a stepping motor attached to the pile at a point located $20 \mathrm{~mm}$ below the pile head using wire. To investigate the response of the pile, seven pairs of strain gauges were attached along the pile. The readings from the stain gauges are obtained using a DH 3815 strain gauge testing instrument.

Two cameras (Canon PowerShotG10) with $4416 \times 3312$ pixels resolution were used to synchronously capture images by a developed software driver using MATLAB commands [18]. One camera was set in front of the model box with its optical axis perpendicular to the vertical profile, and another camera was set above the model box with its optical axis perpendicular to the ground surface, as shown in Figure 1. The built in camera zoom lenses were adjusted to select optimized regions of interest. While applying lateral loads, images of the vertical profile and ground surface were simultaneously captured by the two cameras. The images were employed to

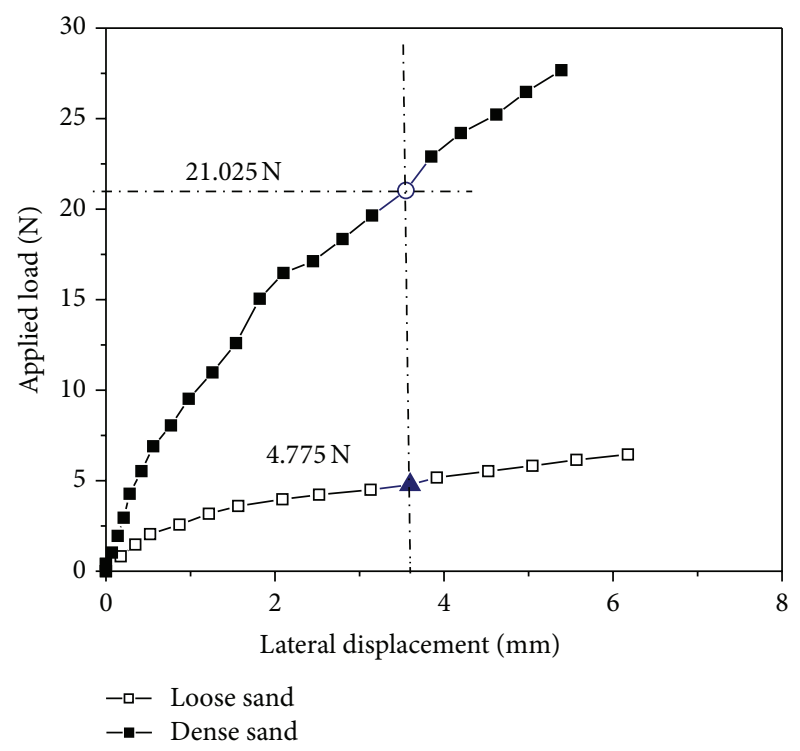

FIGURE 2: Curves of applied load versus lateral displacement in loose and dense sand.

calculate the displacement fields of the vertical profile and ground surface using the PIV technique. More details about the PIV technique can be found in Liu and Iskander [19].

2.2. Soil Properties. The soil deposit was formed using uniform Toyoura sand. Over the past few decades, the properties and stress-strain behaviors of Toyoura sand have been extensively studied by means of diverse laboratory tests. The sand was uniformly fine sand consisting of subrounded to subangular particles. It had the minimum and maximum void ratios of 0.597 and 0.977 , respectively, and a specific gravity of 2.65 [20]. The sand had uniformity coefficient of 1.7 and mean diameter of 0.17 . The critical state friction angle, $\varphi_{c s}$, was $31^{\circ}$ [21]. The loose and dense sand samples were prepared with relative density of $50 \%$ and $80 \%$, respectively.

\section{Test Results and Analysis}

Two model tests of the laterally loaded pile were separately conducted in loose and dense sand. The effect of sand relative density on pile-soil interaction was investigated through the response of the laterally loaded pile and the sand movement around the pile.

3.1. Response of the Laterally Loaded Pile. The curves of applied load versus lateral displacement at the pile head in loose and dense sand are shown in Figure 2. Compared with the two curves, it was clearly found that the lateral bearing capacity in dense sand was larger than that in loose sand. When the lateral displacement was $3.6 \mathrm{~mm}$ (labeled in Figure 2), the applied loads in loose and dense sand were $4.775 \mathrm{~N}$ and $21.025 \mathrm{~N}$, respectively. At this position the response of the laterally loaded pile and the sand displacements were simultaneously measured. 


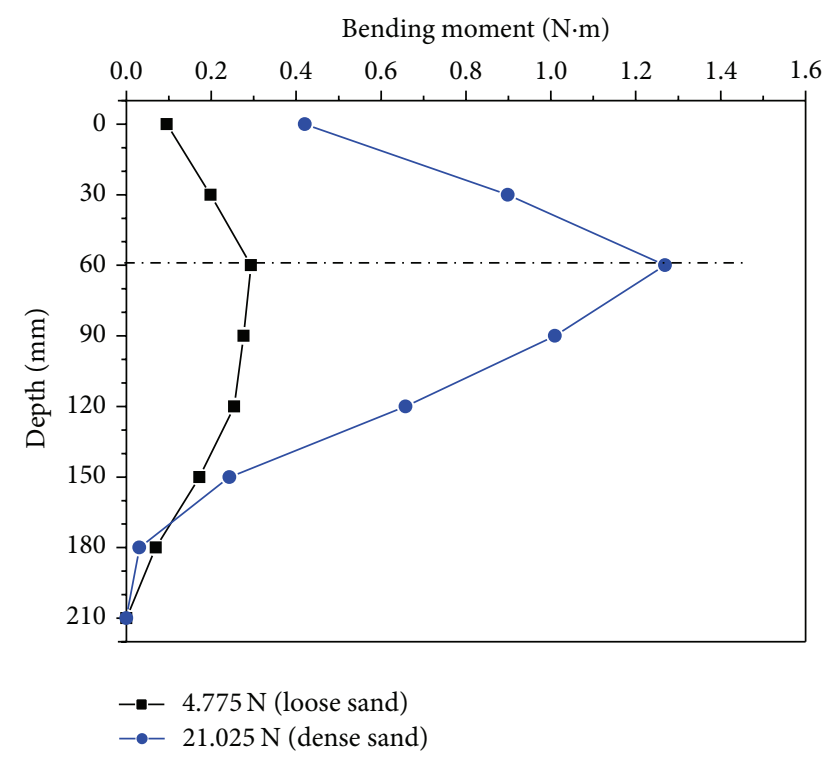

Figure 3: Comparison of the bending moment in loose and dense sand.

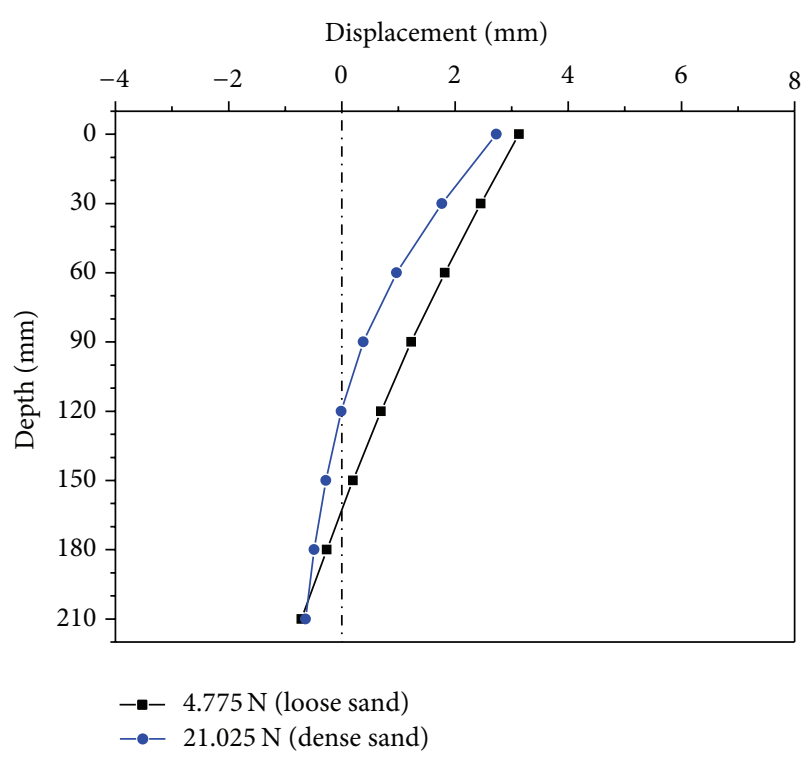

FIgURE 4: Comparison of the pile deflection in loose and dense sand.

The bending moments can be derived from the readings of the strain gauges attached along the model pile. Bending moment distributions along the pile were recorded for a lateral displacement of the pile head at $3.6 \mathrm{~mm}$ (labeled in Figure 2). As shown in Figure 3, the bending moments of the pile in dense sand were larger than those in loose sand. The maximum moment in dense sand was 4.2 times that in loose sand, and the maximum moments were both at the depth of $60 \mathrm{~mm}$ (i.e., 6 times pile width).

The lateral displacements of the model pile can be determined using a double integration method from the moment distribution function. As shown in Figure 4, the lateral displacements along the model pile in dense sand were

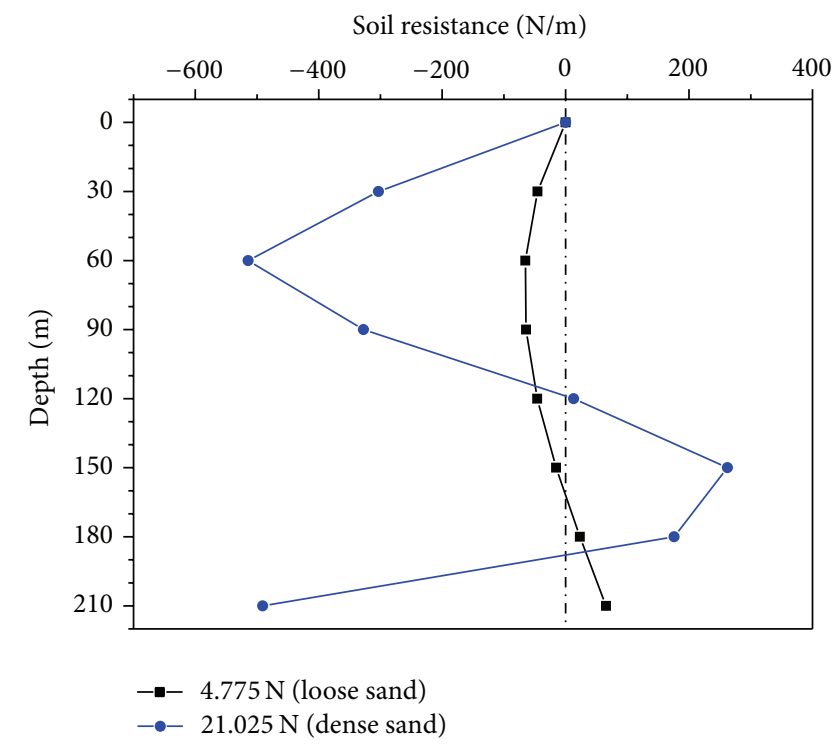

FIgURE 5: Comparison of the soil resistance in loose and dense sand.

less than those in loose sand. The depth of zero deflection in dense sand was also less than that in loose sand. The curve of the pile deflection in loose sand was a straight line; however, the pile in dense sand was flexural deformation, implying that the model pile in dense soil became an elastic pile rather than a rigid pile as occurred in loose sand.

The soil resistances in relation to depth can be interpreted with double differentiation of the bending moment distribution function. The trend of the soil resistances in dense sand was different from that in loose sand, as shown in Figure 5. The soil resistances along the pile in dense sand were larger than those in loose sand, and the maximum resistance in dense sand was 4.8 times that in loose sand, implying that the soil resistances increased with the increasing relative density. With the increasing relative density, the relative stiffness ratio of soil and pile increases, which causes the behavior of the pile to be as an elastic pile.

The $p-y$ curves of the pile in dense and loose sand can be obtained from the aforementioned calculation. As shown in Figure 6, the soil resistance increased as the lateral displacement increased. The increasing ratio of the soil resistance in dense sand was much larger than that in loose sand, implying that the soil resistance coefficient increased with the increasing relative density.

3.2. Soil Deformation around the Laterally Loaded Pile. The pile-soil interaction not only included the response of the laterally loaded pile, but also consisted of the deformation of the soil restraining the pile deflection. When the pile head was under the same lateral displacement of $3.6 \mathrm{~mm}$ in dense and loose sand, the displacement fields of the vertical profile and ground surface were calculated using the PIVview2C software. In the contours of the displacement fields at the vertical profile shown in Figure 7, the maximum displacement of loose sand was 1.5 times that of dense sand, and the influence zone along the depth in loose sand was 


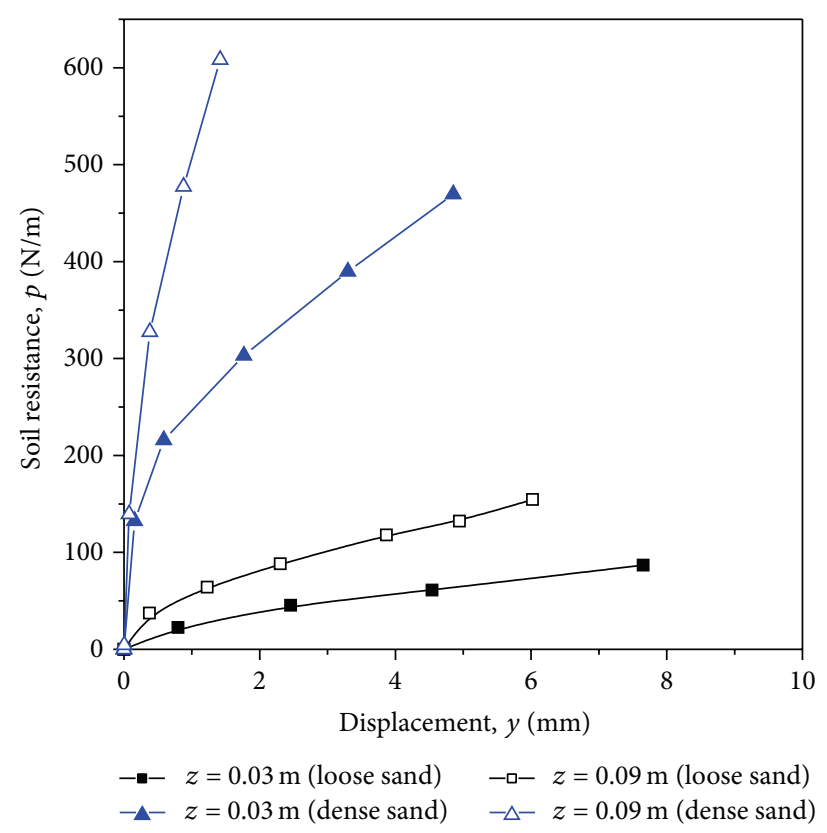

FIgURE 6: Comparison of $p-y$ curves in loose and dense sand.

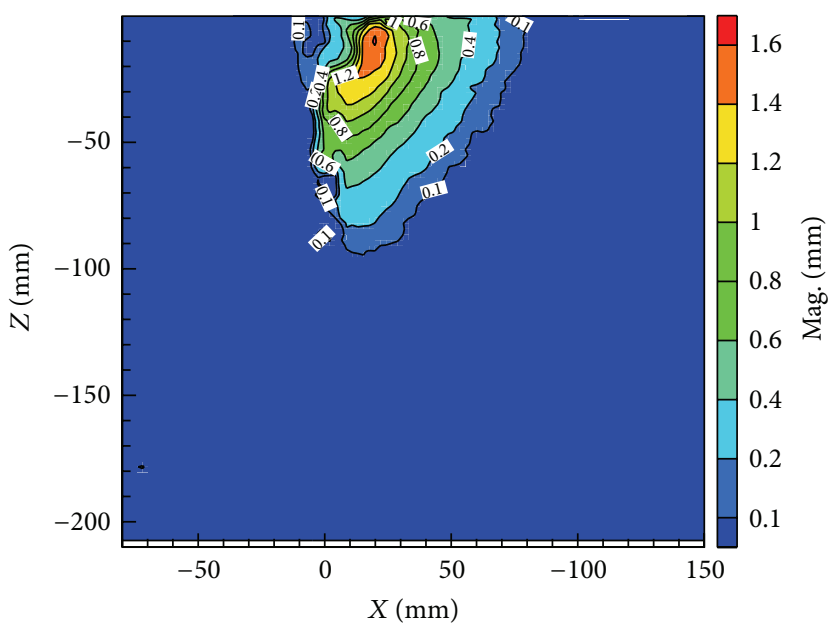

(a)

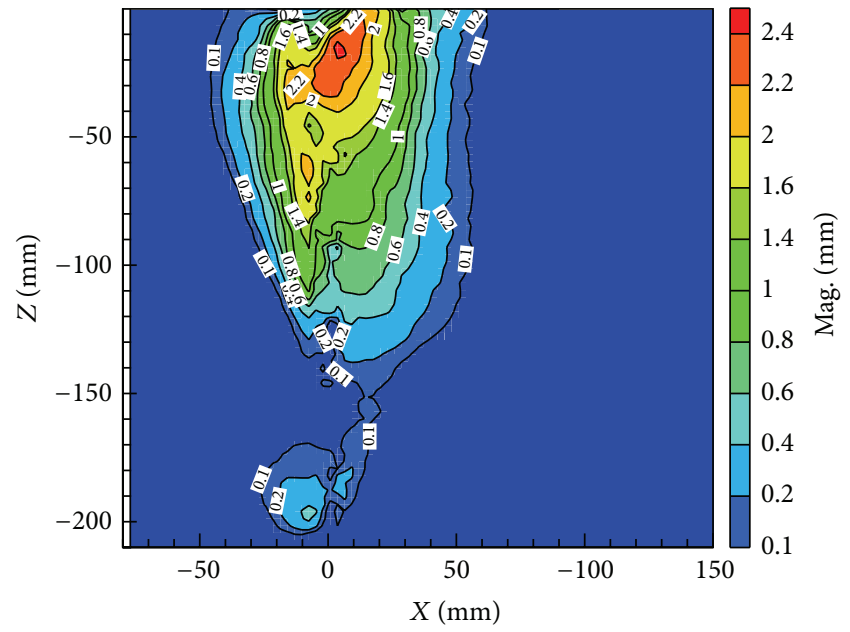

(b)

FIGURE 7: Contours of displacement fields at the vertical profile: (a) contours of displacement field in dense sand; (b) contours of displacement field in loose sand.

obviously larger than that in dense sand. There were two main reasons: (1) the pile displacements in loose sand were larger than those in dense sand shown in Figure 4, and the pile in loose sand pushed the surrounding sand with a larger lateral displacement; (2) the dense sand was compacted; thus, the dense sand particles did not so easily move as the loose sand particles.

Comparing the contours of the displacement fields at the ground surface shown in Figure 8, the maximum displacements were $1.4 \mathrm{~mm}$ in dense sand and $2.4 \mathrm{~mm}$ in loose sand, which was consistent with the contours of the displacement fields at the vertical profile. It was also worth noting that the influence zone of the ground surface in loose sand was larger than that in dense sand, especially within the back of the pile. The loose sand particles easily moved, which caused the soil behind the pile to move downwards duo to diminished resistance of the pile. The compressed sand particles behind the pile were stable, even though losing the resistance of the pile, which was consistent with displacements at the vertical profile shown in Figure 7.

\section{Conclusions}

In this study, two scale-model tests in dense and loose sand were conducted to investigate the effect of relative density 


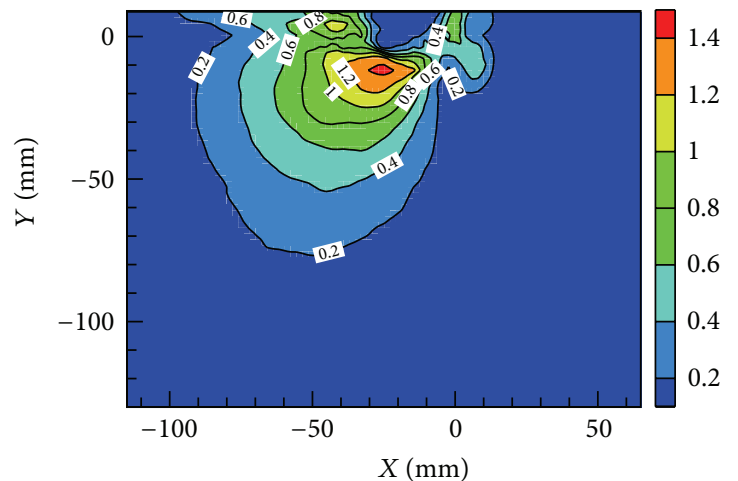

(a)

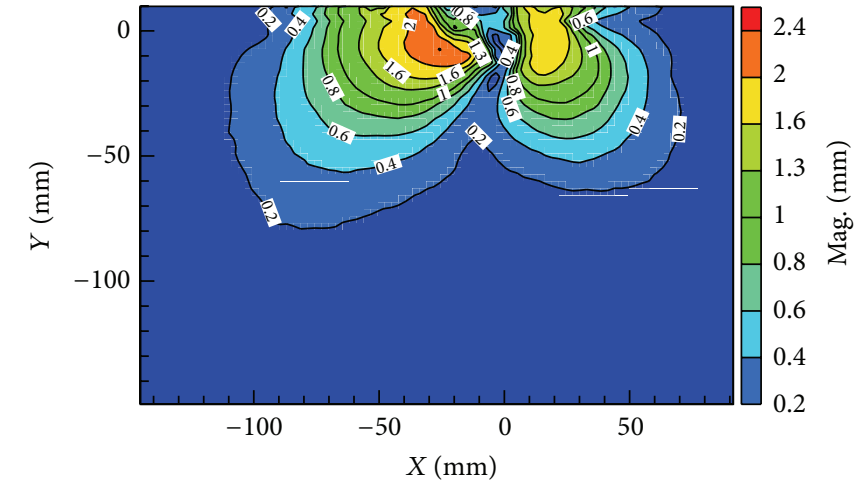

(b)

FIGURE 8: Contours of displacement fields at the ground surface: (a) contours of displacement field in dense sand; (b) contours of displacement field in loose sand.

on the response of a laterally loaded pile and surrounding soil deformation. The bending moment, lateral deflection, and soil resistance distribution along the model pile were derived from the strain measurement. When the same displacement of $3.6 \mathrm{~mm}$ at the loading point of the pile head was reached, the lateral bearing capacity, bending moment, and soil resistance in dense sand were larger than those in loose sand; however, the deflection of the pile in dense sand was less than that in loose sand. The main reason was that the relative stiffness ratio of soil and pile increased with increasing relative density, which caused the behavior of the pile in dense sand to be elastic rather than rigid.

The displacement fields around the laterally loaded pile in the vertical profile and ground surface were simultaneously measured using the PIV technique. At the same displacement of the pile head, the maximum displacements of loose sand in the vertical profile and ground surface were over 1.5 times those of dense sand. In addition, the influence zones along the depth of the pile and the back of the pile in loose sand were obviously larger than those in dense sand. The main reasons were that the pile displacements in loose sand were larger than those in dense sand, the pile in loose sand pushed the surrounding sand with a larger displacement, and the dense sand was compacted; thus, the dense sand particles did not so easily move as the loose sand particles, and the sand particles behind the pile were stable, even though diminishing resistance of the pile.

The results demonstrated that the combined analysis of the response of the pile and the sand displacement fields is appropriate to investigate the mechanism of the effect of relative density on pile-soil interaction. In the future research, the internal sand movement will be observed using transparent soil to investigate the effect of the sand density on the internal pile-soil interaction.

\section{Conflict of Interests}

The authors declared that they have no conflict of interests to this work.

\section{Acknowledgments}

The authors would gratefully like to acknowledge the support provided by the National Natural Science Foundation of China (no. 51308164, no. 51279049, and no. 51304057) and the China Postdoctoral Science Foundation (no. 2013M530157 and no. 2014T70349). The editorial help from Professor Galen Leonhardy of Black Hawk College is also greatly appreciated.

\section{References}

[1] D. Leshchinsky, F. Vahedifard, and C. L. Meehan, "Application of a hydraulic gradient technique for modeling the uplift behavior of piles in sand," Geotechnical Testing Journal, vol. 35, no. 3, pp. 400-408, 2012.

[2] S. K. Suryasentana and B. M. Lehane, "Numerical derivation of CPT-based $p-y$ curves for piles in sand," Geotechnique, vol. 64, no. 3, pp. 186-194, 2014.

[3] A. M. A. Nasr, "Experimental and theoretical studies of laterally loaded finned piles in sand," Canadian Geotechnical Journal, vol. 51, no. 4, pp. 381-393, 2014.

[4] L. Ping, Z. Dong, W. Luo, and G. Qian, "The pressure-field characteristics around porous wind fences: results of a wind tunnel study," Environmental Earth Sciences, vol. 68, no. 4, pp. 947-953, 2013.

[5] B. B. Broms, "Lateral resistance of piles in cohesiveless soils," Journal of the Soil Mechanics and Foundations Division, vol. 90, no. 3, pp. 123-156, 1964.

[6] H. G. Poulos, "Behavior of laterally loaded piles: I-single piles," Journal of the Soil Mechanics and Foundations Division, vol. 97, no. 5, pp. 711-731, 1971.

[7] M. Ashour and H. Ardalan, " $p-y$ curve and lateral response of piles in fully liquefied sands," Canadian Geotechnical Journal, vol. 49, no. 6, pp. 633-650, 2012.

[8] M. Khari, K. A. Kassim, and A. Adnan, "Development of $p$ $y$ curves of laterally loaded piles in cohesionless soil," The Scientific World Journal, vol. 2014, Article ID 917174, 8 pages, 2014.

[9] M. Ashour, G. Norris, and P. Pilling, "Lateral loading of a pile in layered soil using the strain wedge model," Journal of 
Geotechnical and Geoenvironmental Engineering, vol. 124, no. 4, pp. 303-314, 1998.

[10] L.-Y. Xu, F. Cai, G.-X. Wang, and K. Ugai, "Nonlinear analysis of laterally loaded single piles in sand using modified strain wedge model," Computers and Geotechnics, vol. 51, pp. 60-71, 2013.

[11] D. Su, "Resistance of short, stiff piles to multidirectional lateral loadings," Geotechnical Testing Journal, vol. 35, no. 2, pp. 313329, 2012.

[12] J.-S. Chiou, W.-L. Tai, and C.-H. Chen, "Lateral hysteretic behavior of an aluminum model pile in saturated loose sand," Journal of the Chinese Institute of Engineers, Transactions of the Chinese Institute of Engineers, Series A, vol. 37, no. 3, pp. 313-324, 2014.

[13] J. Otani, K. D. Pham, and J. Sano, "Investigation of failure patterns in sand due to laterally loaded pile using X-ray CT," Soils and Foundations, vol. 46, no. 4, pp. 529-535, 2006.

[14] M. Ahmed and M. Iskander, "Analysis of tunneling-induced ground movements using transparent soil models," Journal of Geotechnical and Geoenvironmental Engineering, vol. 137, no. 5, pp. 525-535, 2011.

[15] J. Liu, B. Yuan, V. T. Mai, and R. Dimaano, "Optical measurement of sand deformation around a laterally loaded pile," Journal of Testing and Evaluation, vol. 39, no. 5, pp. 754-759, 2011.

[16] B.-X. Yuan, W.-W. Chen, T. Jiang, Y.-X. Wang, and K.-P. Chen, "Stereo particle image velocimetry measurement of 3D soil deformation around laterally loaded pile in sand," Journal of Central South University, vol. 20, no. 3, pp. 791-798, 2013.

[17] B. Yuan, R. Chen, J. Teng, T. Peng, and Z. Feng, "Effect of passive pile on $3 \mathrm{D}$ ground deformation and on active pile response," The Scientific World Journal, vol. 2014, Article ID 904186, 6 pages, 2014.

[18] B. Yuan, J. Liu, W. Chen, and K. Xia, "Development of a robust Stereo-PIV system for 3-D soil deformation measurement," Journal of Testing and Evaluation, vol. 40, no. 2, pp. 256-264, 2012.

[19] J. Liu and M. Iskander, "Adaptive cross correlation for imaging displacements in soils," Journal of Computing in Civil Engineering, vol. 18, no. 1, pp. 46-57, 2004.

[20] M. Yoshimine, K. Ishihara, and W. Vargas, "Effects of principal stress direction and intermediate principal stress on undrained shear behavior of sand," Soils and Foundations, vol. 38, no. 3, pp. 179-188, 1998.

[21] R. Verdugo and K. Ishihara, "The steady state of sandy soils," Soils and Foundations, vol. 36, no. 2, pp. 81-91, 1996. 

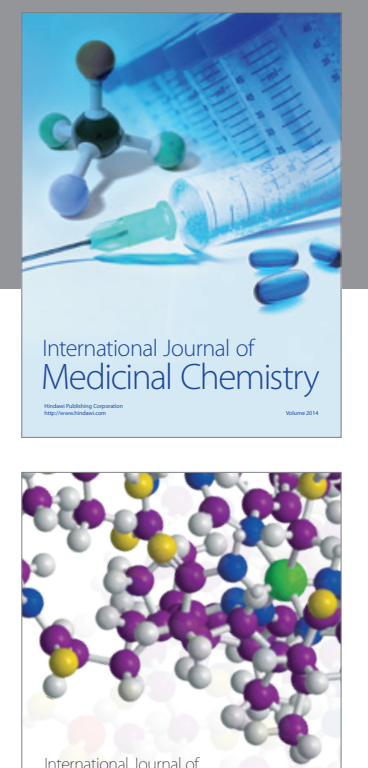

\section{Carbohydrate} Chemistry

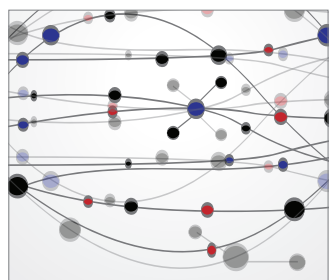

The Scientific World Journal
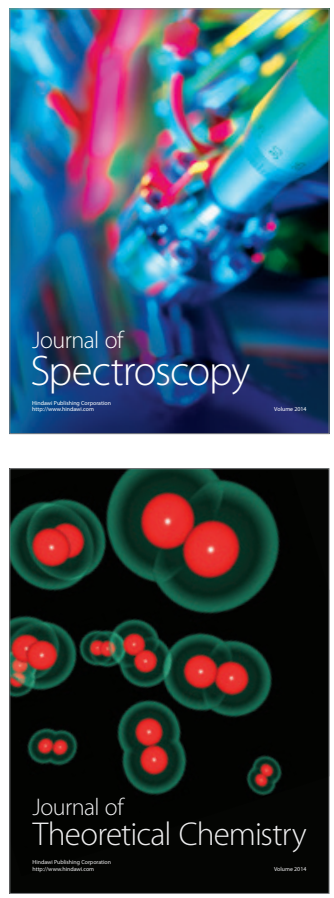
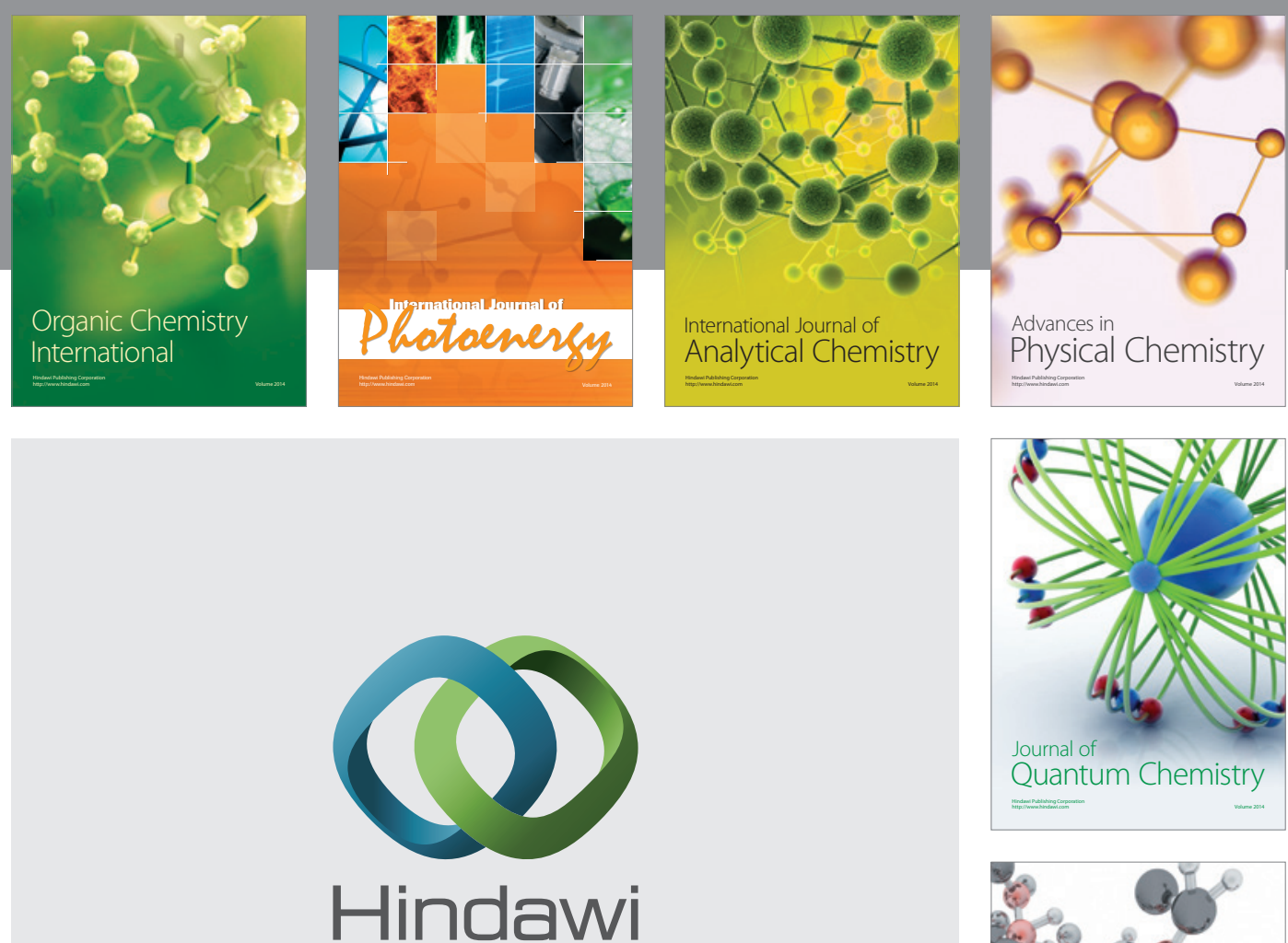

Submit your manuscripts at

http://www.hindawi.com

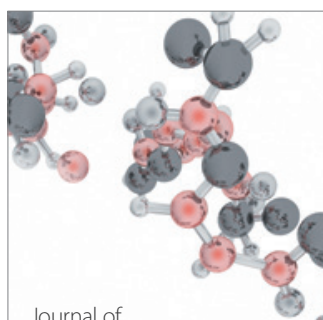

Analytical Methods

in Chemistry

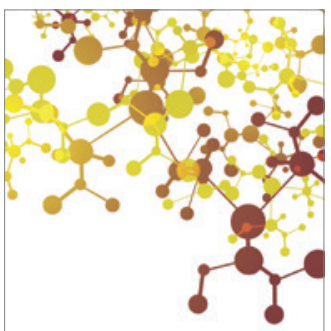

Journal of

Applied Chemistry

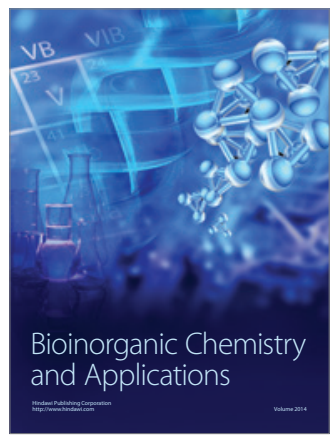

Inorganic Chemistry
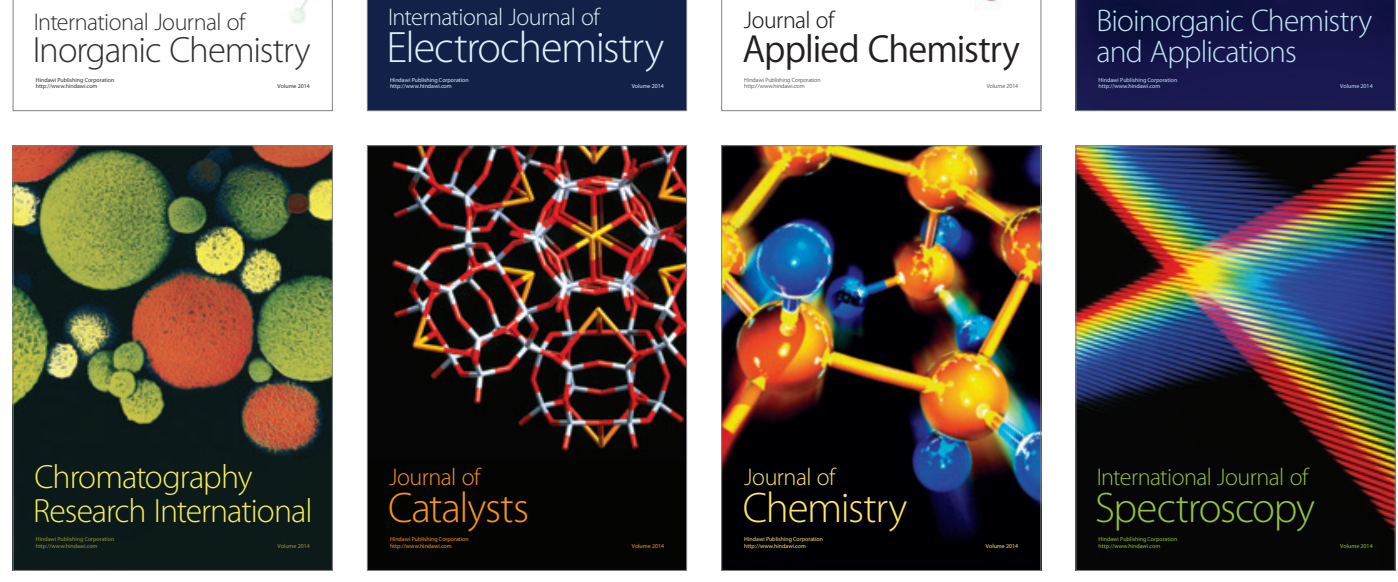